\title{
Aldol Reaction in Water Catalyzed with Polymer-Supported Proline
}

Key words

aldol reaction

prolines

polymer support

1,2,3-triazole linker

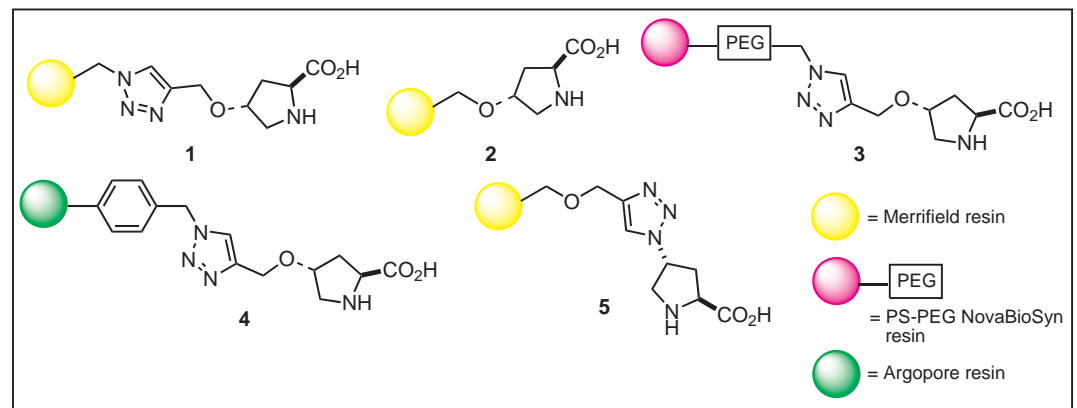

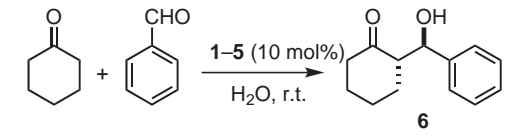

\begin{tabular}{lcccc}
\hline & $\mathrm{t}(\mathrm{h})$ & yield $(\%)$ & anti/syn & ee $(\%)$ \\
\hline $\mathbf{1}(1 \% \mathrm{DVB})$ & 84 & 67 & $95: 5$ & 95 \\
$\mathbf{1}(1 \%$ DVB $)$ & 60 & 58 & $94: 6$ & 92 \\
$\mathbf{2}(2 \%$ DVB $)$ & 60 & 70 & $93: 7$ & 40 \\
$\mathbf{3}$ & 60 & 10 & n.d. & 91 \\
$\mathbf{4}$ & 84 & traces & n.d. & 70 \\
$\mathbf{5}$ & 24 & 74 & $96: 4$ & 98 \\
\hline
\end{tabular}

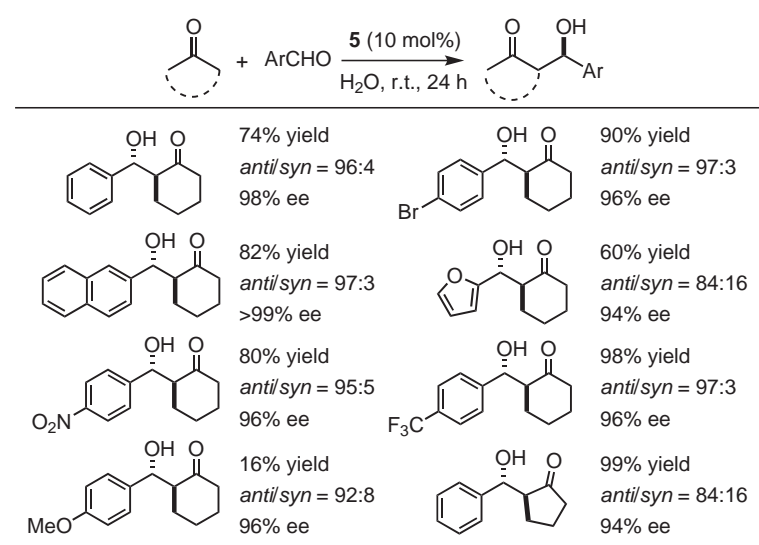

Significance: Polystyrene-support prolines (1-5) were prepared by the cycloaddition of the corresponding azides and alkynes. Prolines 1-5 catalyzed the aldol reaction of cyclohexanone with benzaldehyde in water to give the aldol product 6 in traces to $74 \%$ yield with $40-98 \%$ ee. When proline 5 was used for the reaction, a gel-like single phase was formed in water. Water-swollen proline 5 showed higher catalytic activity for the aldol reaction of cyclohexanone and 4-nitrobenzaldehyde (99\% yield and 96\% ee) than anhydrous 5 (80\% yield and $89 \%$ ee). The aldol reaction of cyclic ketones with various aldehydes was also catalyzed by $\mathbf{5}$ in water at room temperature to afford the corresponding products in 16-99\% yield and 9499\% ee.

SYNFACTS Contributors: Yasuhiro Uozumi, Takao Osako Synfacts 2008, 4, 0427-0427 Published online: 19.03.2008 Dol: 10.1055/s-2008-1042772; Reg-No.: Y02408SF
Comment: In the reaction of cyclohexanone and benzaldehyde, the water-swollen $\mathbf{5}$ was superior in reaction rate and stereoselectivity to the other polymeric prolines 1-4. TGA analysis of the waterswollen $\mathbf{5}$ showed up to $24 \%$ water content in weight. Theoretical calculation suggested that water molecules formed a hydrogen-bonding network between the triazole and the amino acid group in 5. High yields, enantioselectivities, and diastereoselectivities were achieved in the reaction of cyclic ketones and aromatic aldehydes with 5 in water except for the reaction of 4-methoxybenzaldehyde. The catalyst was recycled and reused at least five times without loss of catalytic activity. 